\title{
Report details changes and challenges for women in biomedicine
}

In 1997, a year after becoming a full professor of otolaryngology and pediatrics at the State University of New York (SUNY) in Buffalo, Linda Brodsky offered to help her department chairman prepare for a review of their residency training program. As part of her duties, she reviewed a list of her colleagues' salaries. "I looked at it, and I thought, my God," recalls Brodsky, who at the time was also the director of the department of pediatric otolaryngology at the Children's Hospital of Buffalo. She says she saw that a recently hired nontenured associate professor in her department-a male-was earning twice as much as she was in university and hospital stipends (Brodksy had been at SUNY for 14 years). She says that she dug a little deeper and found that her salary was lower than that of male doctors who were not department chairs in her hospital, too.

Brodsky's discovery fueled a ten-yearlong battle against the university and hospital involving three lawsuits, which were finally resolved in 2007 and 2008. (Brodsky says that SUNY awarded her $\$ 740,000$ and full retirement benefits; the hospital resolutions are confidential.) Perhaps in part because of her vocal campaigns for gender equality over the past decade, the salary gaps between male and female scientists at research universities seem to be shrinking - a National Academy of Sciences (NAS) report published in early June found no salary differences between male and female biomedical scientists in assistant and associate professor positions and an $8 \%$ difference for full professors.
But Brodsky worries that things aren't getting any easier for women on the whole. Among other things, she says, how can tenure-track women in science and medicine raise families with all the time demands? As Kathleen Scotto, vice president of research and acting dean of the Graduate School of Biomedical Sciences at the University of Medicine and Dentistry of New Jersey, noted at a panel hosted by the New York Academy of Sciences on 10 June, "you shouldn't have to give up all the rest of your life to be a scientist."

And it seems that many women aren't willing to. According to the NAS report, women were awarded $45 \%$ of all biology doctorates at research-intensive universities from 1999 to 2003, but only 26\% applied for faculty jobs.

NAS committee co-chair Sally Shaywitz, co-director of the Center for Dyslexia and Creativity at the Yale University School of Medicine, points out that today, scientists are often expected to complete not one, but two, postdoctoral fellowships and notes that "people want to have full, multidimensional lives and want to think about having families. The way the system is, you can't begin to think of doing that until you're in your late 30 s and early 40 s."

The report also highlighted some especially unsettling trends in biology departments. In other scientific disciplines, the percentage of women who received first job offers was higher than the percentage invited for interviews. In biology, women were granted a third of all

\section{NIH pushes for rare disease drugs}

The US National Institutes of Health (NIH) has announced a new $\$ 24$ million program to develop drugs for rare diseases.

Nearly $90 \%$ of potential drugs get ruled out via expensive testing during costly preclinical trials, often dubbed the 'Valley of Death'. For common diseases, going through the valley pays off for pharmaceutical developers. But, drugs for rare diseases seldom have such a payoff, even with incentives offered through the US 1983 Orphan Drug Act.

The new NIH project, called the Therapeutics for Rare and Neglected Diseases program, seeks to set up its own pipeline of facilities and collaborating academic researchers to conduct preclinical and clinical testing.

The project, announced 20 May, is in the early stages of planning, said Stephen Groft, director of the NIH Office of Rare Diseases Research, which oversees the new program. It is currently assembling advisory boards to decide which diseases will be pursued and how to best implement the research.

The NIH estimates that there are more than 6,800 diseases in America that individually affect fewer than 200,000 people but collectively affect more than 25 million. Only about 200 of these diseases have a drug treatment.

Stu Hutson, Gainesville, Florida

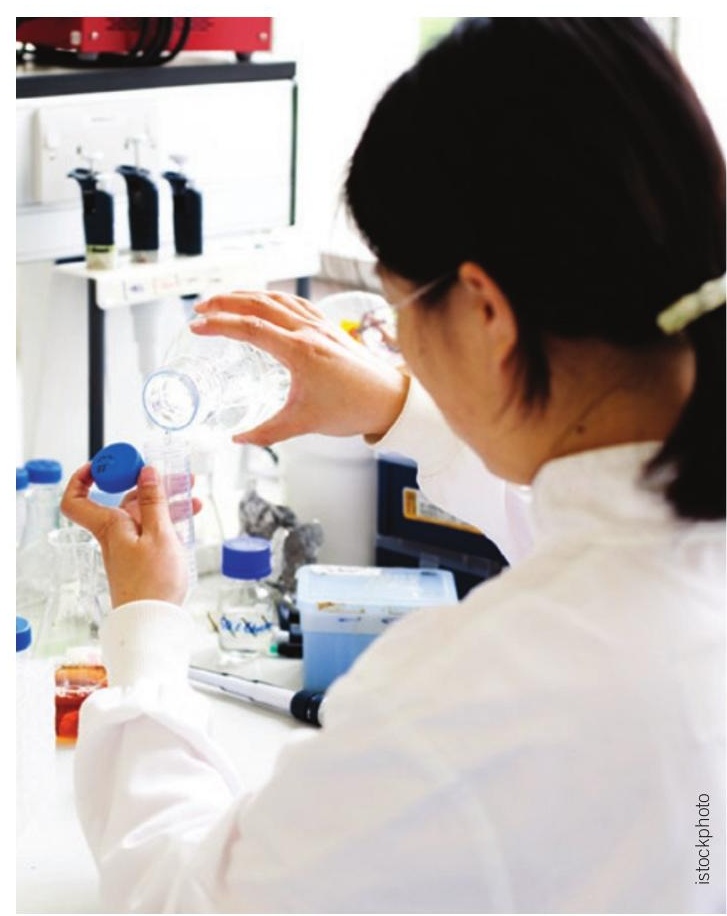

The right mix: Family-friendly plans help

faculty interviews but only received $22 \%$ of the first offers. And those that were in faculty jobs received less funding than their male counterparts.

Shaywitz says that universities can attract more women to academic positions by creating more family-friendly programs, such as stopthe-clock policies and on-site daycare centers. The NAS report revealed that faculty who took advantage of stop-the-clock policies, which allow tenure-track faculty members to extend their probationary periods, spent more time as assistant professors before receiving tenure - on average about a year and a half — but, in the long term, were just as likely to get tenured as those who did not. Mentorship programs also made a big difference: female assistant chemistry professors who had mentors were $18 \%$ more likely to receive grant funding.

Others do not see the leaky pipeline as evidence of a problem requiring 'fixing' at all and say that women are opting against academia because they want to. Until there are longitudinal studies following women throughout their careers, it will be impossible to know why so many women choose against academia. "We really need to know what's happening over time," Shaywitz says. "Is the glass half empty or half full? We don't know yet."

Melinda Wenner, New York 